\title{
Evaluasi Rangkaian Anaerobic Fluidized Bed Reactor (AFBR) dan Micro Bubble Generator (MBG) untuk Pengolahan Air Lindi Sampah
}

\author{
Wiratni Budhijanto *, Sholahuddin Al Ayyubi, Khalid Abdul Latif
}

Grup Riset Teknik Bioproses, Departemen Teknik Kimia, Fakultas Teknik, Universitas Gadjah Mada, Jl. Grafika 2 Yogyakarta 55281

*E-mail: wiratni@ugm.ac.id

Abstrak. Timbulan air lindi adalah masalah serius pada tempat pengolahan sampah akhir (TPA) di Indonesia. Kandungan komponen organik pada sampah Indonesia yang mencapai 70-75\% dari total timbulan sampah menyebabkan tingginya produksi lindi sebagai cairan hasil pembusukan. Studi ini bertujuan mengoptimalkan proses pembersihan air lindi dengan rangkaian proses anaerob yang diikuti dengan proses aerob pada skala mini pilot plant. Peruraian anaerobik dijalankan dalam anaerobic fluidized bed reactor (AFBR) dengan media imobilisasi mikroorganisme yang difluidisasi. Tahap selanjutnya adalah proses peruraian secara aerob dengan aerasi menggunakan micro bubble generator $(M B G)$. Pilot plant yang didirikan di tempat pengolahan akhir (TPA) Piyungan di Yogyakarta ini terdiri atas AFBR dengan volume 500 L dan bak aerasi dengan MBG berukuran 500 L. Pengamatan data kualitas air (soluble chemical oxygen demand (sCOD) dan volatile fatty acid (VFA)) pada input/output AFBR dan input/output MBG serta volume biogas yang dihasilkan di AFBR dilakukan secara berkala selama 70 hari start-up di mana reaktor mulai dioperasikan secara kontinu setelah inokulasi secara batch dan 50 hari operasional pada kondisi steady state. Walaupun telah dioperasikan selama lebih dari sebulan, performa AFBR setelah tercapai kondisi steady state belum optimal karena baru mencapai kurang lebih 30\% pengurangan kandungan senyawa organik. Performa yang lebih baik teramati pada proses aerob dengan aerasi menggunakan $M B G$. Proses tersebut berhasil menurunkan sCOD sampai 60\%. Studi awal ini menunjukkan bahwa rangkaian AFBR dan MBG berpotensi untuk mengatasi masalah pencemaran air lindi di TPA. Optimalisasi kinerja unit ini terutama ditentukan oleh proses start-up yang dipengaruhi oleh teknik inokulasi.

Kata Kunci: fluidisasi, imobilisasi mikrobia, lindi, peruraian aerob, peruraian anaerob, sampah.

\begin{abstract}
Evaluation of Anaerobic Fluidized Bed Reactor (AFBR) and Micro Bubble Generator (MBG) for Landfill Leachate Treatment. Landfill leachate emission is a very serious problem in Indonesian landfill sites. High organic fraction in Indonesian garbage, which accounts for 70-75\% of total municipal solid waste amount, emits high flow rate of leachate as the result of decay process. This study aims to optimize landfill leachate treatment by means of anaerobic process followed by aerobic process. The anaerobic digestion was carried out in AFBR in which microbial immobilization media was fluidized. The next stage was aerobic digestion by applying novel aeration technology using MBG. The pilot plant was installed in Piyungan Landfill Site in Yogyakarta, which consisted of $500 \mathrm{~L} \mathrm{AFBR}$ and $500 \mathrm{~L} \mathrm{MBG}$ units. Observation was conducted periodically for 70 days of start-up when the unit was operated continuously after batch inoculation followed by 50 days of steady-state operation. The measurement was taken as soluble chemical oxygen demand (sCOD) and volatile fatty acids (VFA) on the input/output of AFBR and input/output of MBG. The biogas volume production in the AFBR was also measured. AFBR performance was not optimal since even after achieving a steady state condition (for one-month operation), it could only reduce less than $30 \%$ organic content. A better performance was observed in the aerobic process where $M B G$ was used for the aeration. It could reduce $60 \%$ of $S C O D$. This preliminary study showed that the coupling of AFBR and MBG units is potential for landfill leachate treatment. Optimization of this unit depended on the inoculation technique during the start-up period.
\end{abstract}

Keywords: aerobic digestion, anaerobic digestion, fluidization, landfill leachate, microbial immobilization, municipal solid waste.

\section{Graphical Abstract}

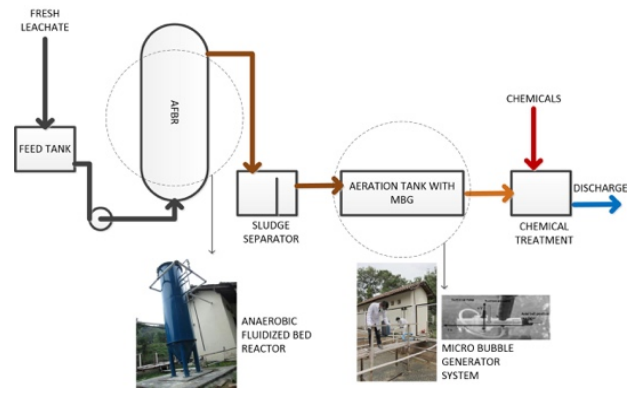




\section{Pendahuluan}

Saat ini Indonesia menghasilkan kurang lebih 30 juta $\mathrm{m}^{3}$ sampah per hari. Berbagai upaya pengurangan sampah di sumbernya belum berhasil sehingga pada dasarnya keseluruhan sampah ini berakhir terakumulasi di tempat pengolahan akhir (TPA) sampah yang kebanyakan masih berupa open dumping, walaupun mulai diupayakan menuju ke sanitary landfill. Di Propinsi Daerah Istimewa Yogyakarta, sebagian besar sampah masuk ke TPA regional yang mencakup Kotamadya Yogyakarta, Kabupaten Sleman, dan Kabupaten Bantul. Jumlah sampah yang masuk ke TPA Piyungan DIY menurut data tahun 2017 mencapai 400-500 ton/hari (Satker PSPLP, 2017).

Salah satu hal yang merupakan keunikan sampah di Indonesia dibanding sampah di negara maju adalah sampah yang terkumpul di TPA ini memiliki kandungan bahan organik dan air yang tinggi. Proses pembusukan sampah yang didominasi fraksi organik ini menyebabkan munculnya limbah cair yang biasa disebut lindi. Lindi merupakan limbah cair yang timbul selama proses pembusukan akibat perkolasi air eksternal (misal air hujan) ke dalam tumpukan sampah yang melarutkan berbagai macam bahan organik maupun anorganik dalam sampah. Lindi biasanya mengandung berbagai senyawa organik tetapi juga mengandung senyawa-senyawa anorganik seperti berbagai kation mengingat kondisi sampah Indonesia yang tidak terpilah sama sekali. Hal ini menyebabkan lindi sangat berbahaya bagi lingkungan terutama karena beresiko mencemari sumber-sumber air di sekitar TPA.

Air lindi di TPA Piyungan masih diolah secara aerobik konvensional dengan menggunakan 7 kolam pengolahan dengan aerator di salah satu kolam. Sistem pengolahan lindi menggunakan kolam-kolam tersebut belum berfungsi dengan baik sehingga Pemerintah DIY terpaksa mengambil solusi cepat dengan penambahan volume kolam untuk menanggulangi meningkatnya jumlah air lindi yang dihasilkan. Hal ini tentu saja tidak bisa dibiarkan karena lahan yang tersedia di TPA Piyungan tidak memadai untuk perluasan kolam. Kendala lain adalah kebutuhan energi yang sangat tinggi untuk mengoperasikan aerator sehingga jumlah aerator yang dipasang sangat tidak memadai.

Studi ini bertujuan mengevaluasi sebuah pilot plant yang terdiri atas anaerobic fluidized bed reactor (AFBR) dan unit aerob dengan aerasi menggunakan micro bubble generator (MBG) untuk mengatasi masalah air lindi di TPA Piyungan (Gambar 1). Rancangan unit ini didasarkan pada penelitian terdahulu tentang $A F B R$ untuk pengolahan lindi pada skala laboratorium (Guntama dkk., 2016; Prastyo dkk., 2017; Sudibyo dkk., 2016) dan aplikasi $M B G$ untuk aerasi pengolahan limbah secara aerob pada skala laboratorium (Deendarlianto dkk., 2015; Budhijanto dkk., 2015).

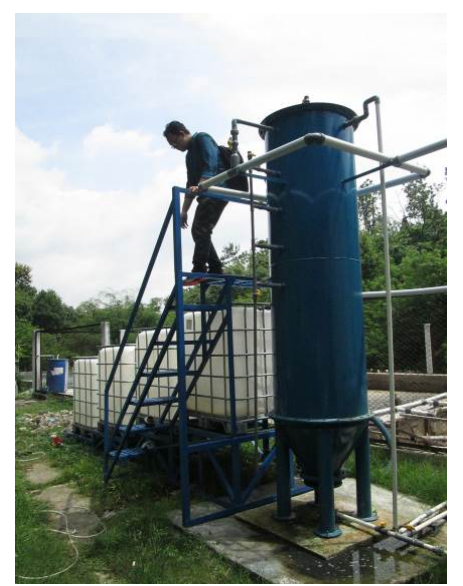

Gambar 1. Rangkaian AFBR dan unit MBG skala mini pilot plant di TPA Piyungan Yogyakarta

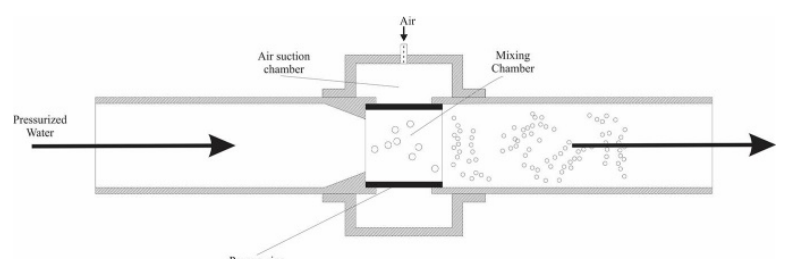

Gambar 2. Skema MBG dalam penelitian ini yang merupakan modifikasi dari MBG yang dikembangkan oleh Sadatomi dkk. (2012)

Tabel 1. Karakteristik fisis zeolit Tasikmalaya (Chusna dkk., 2018)

\begin{tabular}{cc}
\hline Parameter & Nilai \\
\hline Diameter pori rerata & $67,643 \AA$ \\
Luas permukaan & $8,585 \mathrm{~m}^{2} / \mathrm{g}$ \\
Volume pori total & $0,029 \mathrm{cc} / \mathrm{g}$ \\
Komposisi (\% massa) & \\
$\mathrm{C}$ & 12.59 \\
$\mathrm{Al}_{2} \mathrm{O}_{3}$ & 13.56 \\
$\mathrm{SiO}_{2}$ & 63.03 \\
$\mathrm{P}_{2} \mathrm{O}_{5}$ & 0.15 \\
$\mathrm{SO}_{3}$ & 0.82 \\
$\mathrm{~K}_{2} \mathrm{O}$ & 2.41 \\
$\mathrm{CaO}$ & 1.77 \\
$\mathrm{TiO}$ & 0.50 \\
$\mathrm{FeO}$ & 4.43 \\
$\mathrm{CoO}$ & 0.01 \\
$\mathrm{NiO}$ & 0.27 \\
$\mathrm{ZnO}$ & 0.09 \\
$\mathrm{MoO}$ & 0.18 \\
\hline
\end{tabular}

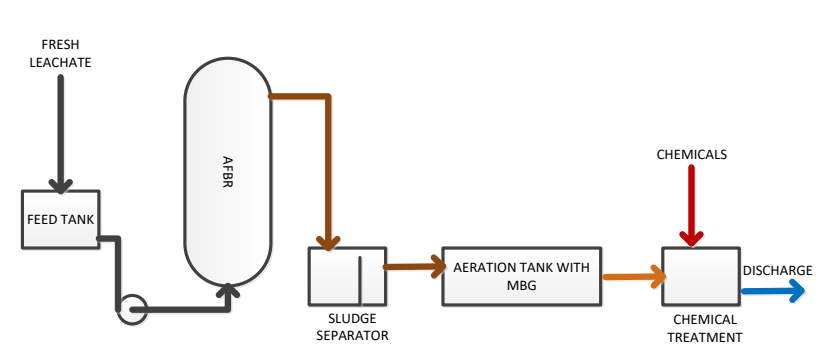

Gambar 3. Skema rangkaian AFBR dan MBG di TPA Piyungan Yogyakarta (Latif, 2018) 

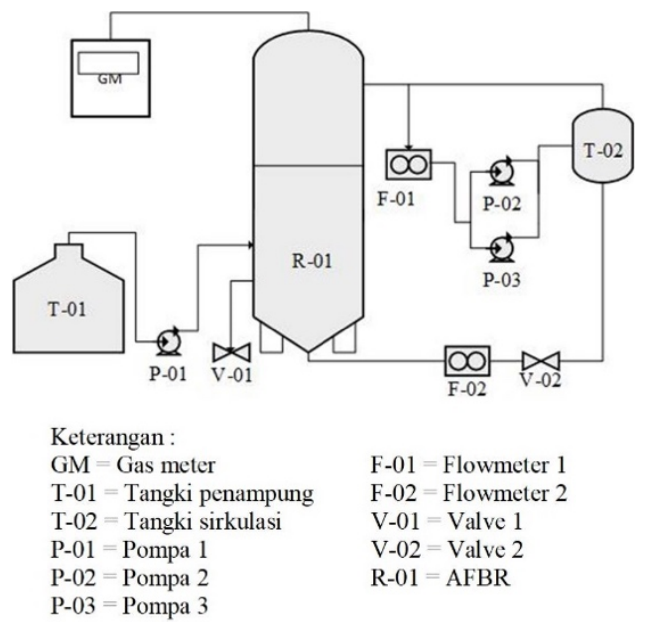

Gambar 4. Skema instalasi AFBR di pilot plant TPA Piyungan Yogyakarta (Al-Ayyubi, 2017)

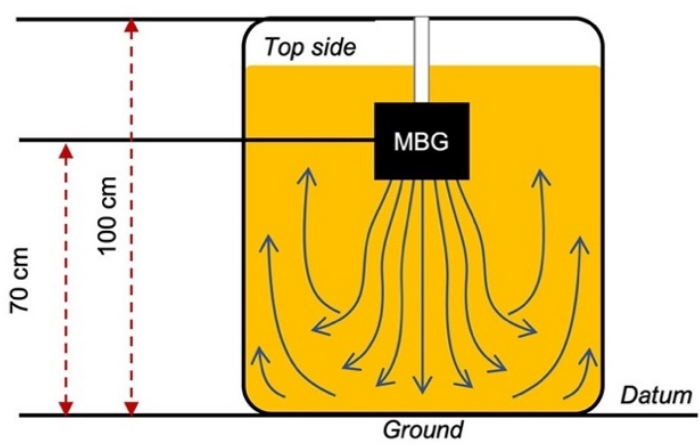

Gambar 5. Skema instalasi MBG di pilot plant TPA Piyungan Yogyakarta

Penggunaan AFBR didasarkan pada pertimbangan utama yaitu reaktor yang tertutup dan kedap udara untuk mengurangi gangguan bau, kemampuannya memproses input dengan kandungan organik cukup tinggi hingga $40-60 \mathrm{~kg} / \mathrm{m}^{3} /$ hari, dan konstruksi vertikal yang tidak memerlukan lahan yang luas jika dibandingkan dengan kolam-kolam yang digunakan saat ini (Liu dkk., 2010; Luo dkk., 2014). Partikel zeolit alam yang digunakan sebagai media imobilisasi bakteri anaerob yang difluidisasi di dalam AFBR membantu memperkuat ketahanan bakteri terhadap fluktuasi kondisi input lindi melalui pembentukan biofilm pada permukaan media.

Aerasi dengan MBG dipilih karena teknologi MBG lebih hemat energi dan mampu menghasilkan kadar oksigen terlarut yang lebih tinggi daripada aerator konvensional (Sadatomi dkk., 2012). Skema MBG diilustrasikan pada Gambar 2. Berbeda dengan kebanyakan aerator yang menggunakan kompresor untuk mendorong udara masuk ke air, MBG menggunakan prinsip aliran fluida dan perbedaan tekanan akibat fluida melalui orifice dalam pipa. Pada jarak tertentu dari orifice, tekanan sangat rendah sehingga udara akan terhisap masuk dan langsung terdorong oleh aliran air sehingga membentuk gelembung berukuran mikro.

\section{Metodologi}

Pada penelitian ini, air lindi diolah melalui 2 tahapan proses yaitu penguraian secara anaerobik diikuti pengolahan aerobik dalam skala pilot plant (Gambar 3). Proses anaerobik terjadi di dalam AFBR, sedangkan proses aerobik terjadi di dalam tangki yang dilengkapi MBG. Skema AFBR secara lebih terperinci diilustrasikan pada Gambar 4, sementara skema MBG disajikan pada Gambar 5. AFBR berupa kolom vertikal dengan ukuran diameter $0,5 \mathrm{~m}$ dan ketinggian $2 \mathrm{~m}$, dengan working volume $0,5 \mathrm{~m}^{3}$. Kecepatan input AFBR diatur sebesar $0,5 \mathrm{~m}^{3} /$ hari sehingga hydraulic retention time (HRT) sebesar 1 hari. Overflow dari AFBR masuk ke tangki $M B G$. Working volume pada tangki $\mathrm{MBG}$ kurang lebih sama dengan AFBR.

Komposisi air lindi yang masuk ke dalam rangkaian AFBR dan MBG ini berfluktuasi tergantung kondisi lindi segar yang keluar dari tumpukan sampah di TPA Piyungan. Selama studi ini dilakukan, konsentrasi $s C O D$ berkisar $3000-5000 \mathrm{mg} / \mathrm{L}$ dengan nilai $\mathrm{pH} 7,8-8,2$. Zeolit yang digunakan sebagai media imobilisasi dalam $A F B R$ adalah zeolit asal Tasikmalaya dengan ukuran partikel 2-2,5 mm. Ukuran ini dipilih berdasarkan homogenitas fluidisasi yang dihasilkan (Ramadhani dkk, 2017). Berdasarkan penelitian sebelumnya (Chusna dkk., 2018), zeolit Tasikmalaya dipilih karena kekuatan mekanis yang terbaik sehingga tidak mengalami abrasi akibat fluidisasi dalam reaktor. Karakteristik zeolit Tasikmalaya yang digunakan dalam studi ini disajikan pada Tabel 1 (Chusna dkk., 2018).

Pengoperasian rangkaian instalasi ini dimulai dengan tahap start-up pada AFBR. Mula-mula reaktor diisi dengan campuran lindi dan inokulum sebanyak $60 \%$ volum lindi dan $40 \%$ inokulum berupa efluen digester kotoran sapi. Jenis inokulum serta rasio antara lindi dan inokulum didasarkan pada komposisi optimum yang telah diperoleh pada penelitian sebelumnya (Shabrina dan Budhijanto, 2015). Efluen digester aktif yang digunakan dalam studi ini memiliki kandungan $s C O D 10.000 \mathrm{mg} / \mathrm{L}$ dengan total plate count mikrobia anaerob sebanyak $5 \times 10^{5} \mathrm{CFU} / \mathrm{mL}$. Campuran ini kemudian disirkulasi secara batch (tanpa input dan output) sampai pembentukan gas mulai terukur di gas meter. Setelah pembentukan biogas mulai stabil, input lindi segar mulai dialirkan dengan waktu tinggal $(H R T) 1$ hari. Mula-mula konsentrasi sCOD dan VFA pada output AFBR masih berubahubah sampai akhirnya reaktor bisa stabil dengan konsentrasi output hampir konstan. Pada saat stabilitas tercapai, maka tahapan start-up dianggap sudah selesai dan pengamatan proses steady state dijalankan selama 50 hari.

Pada saat AFBR sudah beroperasi steady-state, tangki MBG mulai dioperasikan. Untuk proses aerob, proses start-up dilakukan menggunakan inokulum berupa sludge kolam aerob di Instalasi Pengolah Air Limbah (IPAL) komunal Yogyakarta. Start-up proses aerob relatif lebih cepat dibandingkan dengan AFBR. Setelah 5 hari dioperasikan secara batch, penurunan sCOD mulai stabil sehingga selanjutnya tangki MBG 
dioperasikan secara kontinu. Panjang HRT di tangki MBG mengikuti HRT di AFBR karena input hanya merupakan overflow dari AFBR.

\section{Hasil dan Pembahasan}

\subsection{Tahapan start-up AFBR}

Proses start-up dievaluasi secara kualitatif berdasarkan data profil pengurangan sCOD dalam AFBR, perbandingan nilai VFA pada input dan output AFBR, serta produksi biogas. Gambar 6 menunjukkan pengurangan $s C O D$ pada AFBR pada 70 hari pertama AFBR dijalankan secara kontinu dengan HRT 1 hari. Periode HRT 1 hari terhitung sangat singkat untuk proses anaerob jika dibandingkan dengan proses anaerob digester konvensional yang pada umumnya berkisar di HRT 20-30 hari (Siddique dan Wahid, 2018; Kariyama dkk., 2018). Pada Gambar 6 terlihat bahwa di awal periode start-up, penurunan sCOD sangat besar sampai kurang lebih 10 hari pertama. Hal ini disebabkan karena kondisi populasi mikroorganisme di dalam AFBR masih ideal setelah periode inokulasi secara batch di mana efek inhibitor dari air lindi tidak terlalu terasa akibat $40 \%$ reaktor terisi efluen digester kotoran sapi sebagai inokulum yang komposisinya ideal. Setelah 10 hari, pengurangan sCOD di dalam AFBR tidak sebesar sebelumnya dan akhirnya mencapai kestabilan di angka $20-30 \%$.

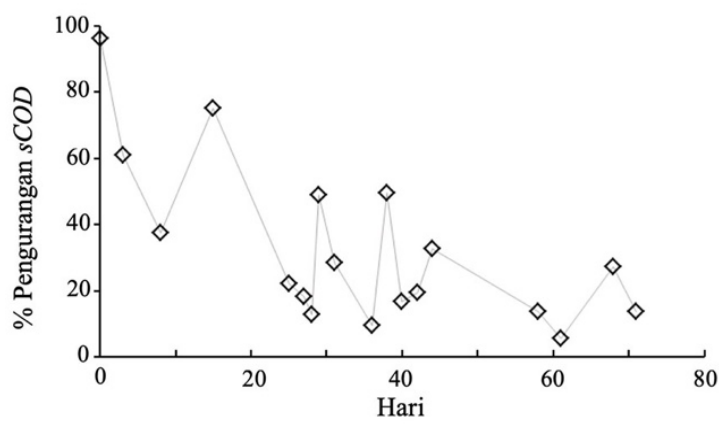

Gambar 6. Profil penghilangan sCOD pada AFBR selama periode start-up (HRT 1 hari)

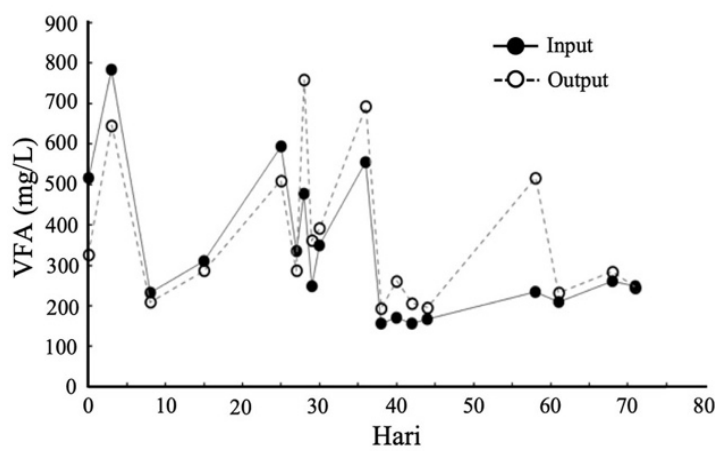

Gambar 7. Profil VFA pada AFBR selama periode start-up (HRT 1 hari)

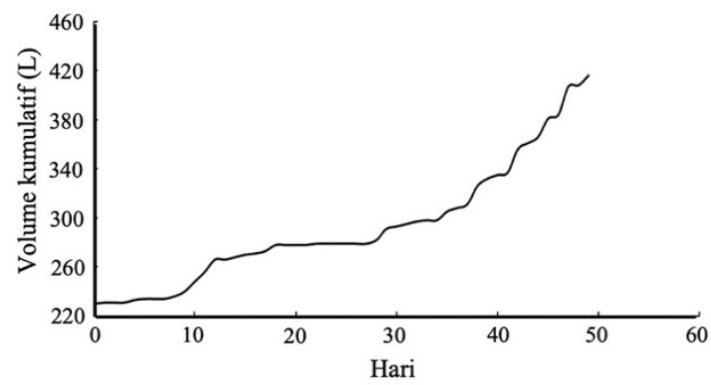

Gambar 8. Volum kumulatif biogas AFBR TPA Piyungan selama periode start-up (HRT 1 hari)

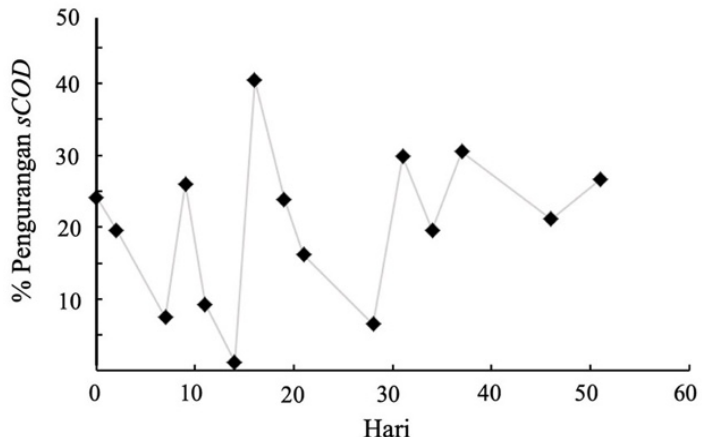

Gambar 9. Profil penghilangan sCOD pada AFBR pada steady-state (HRT 1 hari)

Selanjutnya pada Gambar 7, disajikan profil $V F A$ pada input dan output $A F B R$. Secara umum, teramati kecenderungan bahwa nilai $V F A$ meningkat di dalam $A F B R$. Hal ini menunjukkan bahwa proses asidogen (peruraian senyawa organik menjadi asam-asam karboksilat) yaitu tahapan pertama dalam proses anaerob sudah terjadi di dalam periode start-up ini dan mengindikasikan keberhasilan proses anaerob. Akan tetapi penurunan $s C O D$ yang masih rendah menunjukkan bahwa proses asidogen belum optimal selama 70 hari start-up ini.

Produksi biogas pada $A F B R$ yang disajikan pada Gambar 8 mengkonfirmasi bahwa proses anaerobik sudah berjalan di dalam $A F B R$ pada periode start-up ini, walaupun data $S C O D$ menunjukkan bahwa proses belum berjalan optimal. Walaupun demikian, karena pengurangan $s C O D$ sudah mencapai angka konstan, dianggap proses sudah mencapai kondisi steady state. Hal ini ditunjukkan pada bagian selanjutnya bahwa nilai pengurangan sCOD sudah tidak berubah lagi.

\subsection{Tahapan steady-state: rangkaian AFBR dan MBG \\ Gambar 9 menunjukkan bahwa setelah tahapan} start-up selama 70 hari, nilai pengurangan $s C O D$ sudah tidak berubah lagi. Hari ke-nol pada Gambar 9 adalah hari pertama di mana $A F B R$ dianggap sudah memasuki tahap steady-state sebagai kelanjutan dari tahapan start-up yang disajikan pada Gambar 6-8. Walaupun ada fluktuasi, secara umum pengurangan $s C O D$ berkisar di nilai 20-30\%. Sebuah $A F B R$ ideal seharusnya bisa mencapai pengurangan $s C O D$ sampai 70-80\% (Ghani dan Idris, 2009). Masih rendahnya pengurangan $S C O D$ pada $A F B R$ untuk pengolahan air 
lindi kemungkinan disebabkan karena kandungan inhibitor dalam air lindi yang bervariasi setiap saat.

Setelah AFBR mencapai stabilitas operasional, output dari AFBR mulai masuk ke tangki aerob dengan MBG. Gambar 10 menyajikan komparasi nilai sCOD pada rangkaian AFBR dan $\mathrm{MBG}$, yaitu nilai sCOD pada input AFBR, output AFBR (atau input MBG), dan output MBG yang berturut-turut dinyatakan sebagai "Input", "Out An", dan "Out Ae" pada Gambar 10. Gambar 11 adalah hasil analisis sampel yang sama untuk nilai VFA. Berdasarkan data pada Gambar 10 dan Gambar 11, terlihat bahwa proses aerob di MBG memerlukan waktu kurang lebih 30 hari periode startup untuk stabilisasi populasi mikrobia. Gambar 12 menunjukkan bahwa produksi biogas juga baru mulai stabil setelah kurang lebih 30 hari dari awal start-up. Setelah 30 hari, proses aerob di tangki MBG sudah berhasil menurunkan $s C O D$ sebesar 50-60\%.

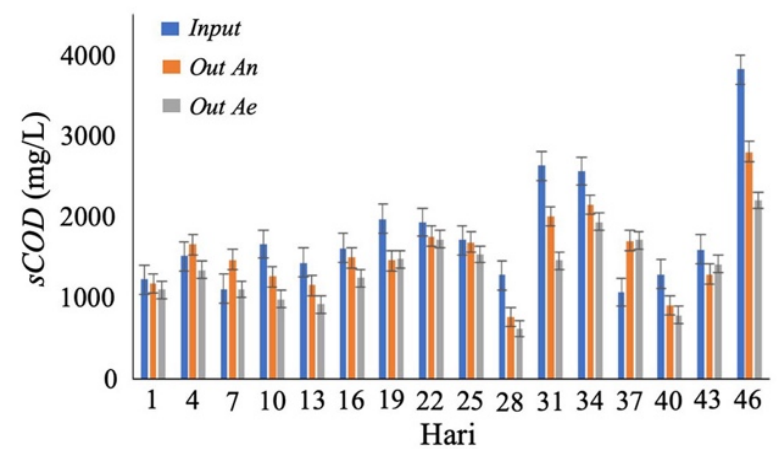

Gambar 10. Profil $s C O D A F B R$ dan $M B G$ selama periode steady-state (HRT 1 hari)

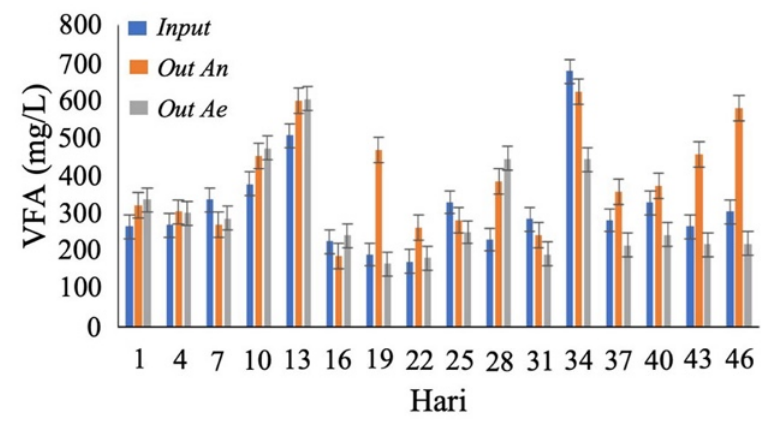

Gambar 11. Profil $V F A A F B R$ dan $M B G$ selama periode steady-state (HRT 1 hari)

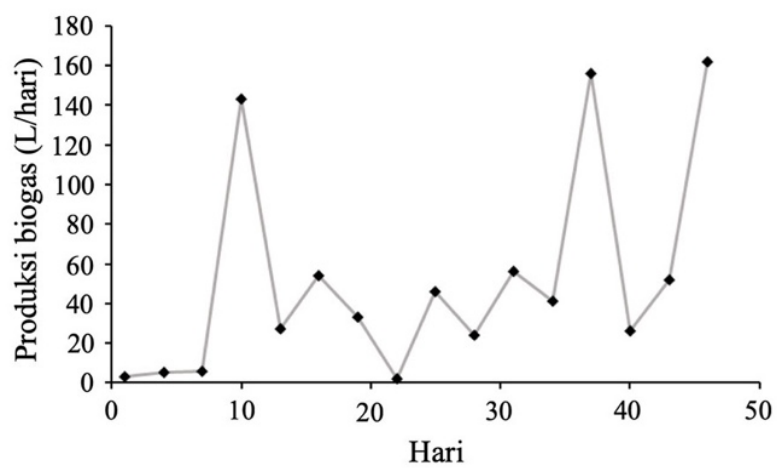

Gambar 12. Produksi biogas dalam $A F B R$ selama periode steady-state (HRT 1 hari)

\section{Kesimpulan}

Rangkaian AFBR dan MBG skala mini pilot plant di TPA Piyungan menunjukkan potensi untuk menurunkan kandungan senyawa organik dalam air lindi sampah. Proses start-up pada AFBR memerlukan waktu dua kali lipat lebih panjang daripada proses start-up pada MBG. Walaupun telah dioperasikan selama lebih dari sebulan, performa AFBR setelah tercapai kondisi steady state belum optimal karena baru mencapai kurang lebih 30\% pengurangan kandungan senyawa organik. Performa yang lebih baik teramati pada proses aerob dengan aerasi menggunakan $\mathrm{MBG}$, yaitu berhasil menurunkan sCOD sampai $60 \%$ dari nilai awal. Walaupun proses AFBR belum optimal pada mini pilot plant di TPA Piyungan, instalasi AFBR sebelum lindi masuk ke unit aerasi tetap direkomendasikan karena AFBR bisa menstabilkan fluktuasi konsentrasi dan kandungan inhibitor dalam air lindi dan menghindarkan unit aerasi dari shock, sehingga secara keseluruhan lebih efektif mengolah air lindi dibandingkan hanya kolam-kolam besar seperti kondisi saat ini di TPA Piyungan.

\section{Ucapan Terima Kasih}

Riset ini dibiayai oleh USAID PEER-Science Research Grant (NAS Sub-Grant Award Letter Agreement Number 2000004934 and Sponsor Grant Award Number AID-OAA-A-11-00012). Pelaksanaan riset di TPA Piyungan dalat terselenggara dengan baik atas dukungan Pemerintah DIY melalui Dinas Pekerjaan Umum, Perumahan, dan ESDM, Balai PISAMP, dan pengelola TPA Piyungan di Sitimulyo, Bantul, Propinsi DIY.

\section{Daftar Pustaka}

Al-Ayyubi, S., Optimasi Pilot Plant Anaerobic Fluidized Bed Reactor untuk Penanganan Lindi Sampah di TPST Piyungan Yogyakarta. Laporan Penelitian, Laboratorium Teknik Pangan dan Bioproses, Departemen Teknik Kimia, Fakultas Teknik, Universitas Gadjah Mada, Yogyakarta, 2017.

Budhijanto, W.; Deendarlianto, D.; Kristiyani, H.; Satriawan, D., Enhancement of Aerobic Wastewater Treatment by the Application of Attached Growth Microorganisms and Microbubble Generator. International Journal of Technology, 2015, 6(7), 1101-1109.

Chusna, F.M.A.; Mellyanawaty, M.; Cahyono, R.B.; Budhijanto, W., Cation Modification of Zeolit as Microbial Immobilization Media in Anaerobic Digestion Process of Palm Oil Mill Effluent (POME). Proceeding of $12^{\text {th }}$ South East Asia Technical University Consortium (SEATUC) Symposium, Universitas Gadjah Mada, Yogyakarta, 12-13 March, 2018 . 
Deendarlianto, D.; Wiratni, W.; Tontowi, A.; Indarto, I.; Iriawan, A., The Implementation of a Developed Microbubble Generator on the Aerobic Wastewater Treatment. International Journal of Technology, 2015, 6(6), 924-930.

Eaton, A.D.; Clesceri, L.; Rice, E.W.; Greenberg, A. (Ed.), Standard Methods for the Examination of Water and Wastewater $25^{\text {th }}$ ed. Franson, M.A., ed., pp. 5-16, 5-58; Washington DC: American Public Health Association, 2005.

Ghani, A.K.; Idris, A., Preliminary Study of Biogas Production from Municipal Solid Waste Leachate. Journal of Engineering Science and Technology, 2009, 4, 374-380.

Guntama, D.; Sudibyo, H.; Budhijanto, W., Landfill Leachate Digestion Using Single Stage Anaerobic Fluidized Bed Bioreactor with Natural Zeolit Powder as Microbial Immobilization Medium. Proceedings of International Seminar on Chemical Engineering in Conjunction with Seminar Teknik Kimia Soehadi Reksowardojo (STKSR) 2016, Bandung, 27-28 October 2016.

Kariyama, I.D.; Zhai, X.; Wu, B., Influence of Mixing on Anaerobic Digestion Efficiency in Stirred Tank Digesters: A review. Water Research, 2018, 143, 503317.

Latif, K.A., Optimasi Pilot Plant Anaerobic Fluidized Bed Reactor dan Microbubble Generator untuk Penanganan Lindi di Tempat Pengolahan Sampah Terpadu (TPST) Piyungan Yogyakarta. Laporan Penelitian, Laboratorium Teknik Pangan dan Bioproses, Departemen Teknik Kimia, Fakultas Teknik, Universitas Gadjah Mada, Yogyakarta, 2018.

Liu, J.; Zhong, J.; Wang, Z.; Liu, Q.; Qian, G.; Zhong, L.; Guo, R.; Zhang, P.; Xu, Z.P., Effective BioTreatment of Fresh Leachate from Pretreated Municipal Solid Waste in An Expanded Granular Sludge Bed Bioreactor. Bioresource Technology, 2010, 101(5), 1447-1452.

Luo, J.; Lu, X.; Liu, J.; Qian, G.; Lu, Y., Biogas Recirculation for Simultaneous Calcium Removal and
Biogas Purification Within An Expanded Granular Sludge Bed System Treating Leachate. Bioresource Technology, 2014, 173, 317-323.

Prastyo, E.; Sudibyo, H.; Budhijanto, W., Determination of the Optimum Hydraulic Retention Time in Two-Stage Anaerobic Fluidized Bed Bioreactor for Landfill Leachate Treatment. Journal of Engineering and Technological Sciences, 2017, 49(3), 388-399.

Ramadhani, L.I.; Damayanti, S.I.; Sudibyo, H.; Budhijanto, W., Kinetics of Anaerobic Digestion of Palm Oil Mill Effluent (POME) in Double Stage Batch Reactor with Recirculation and Fluidization of Microbial Immobilization Media. Proceeding of Quality in Research (QiR) 15 ${ }^{\text {th }}$, Nusa Dua, Bali, 24-27 July, 2017.

Sadatomi, M.; Kawahara, A.; Matsuura, H.; Shikatani, S., Micro-Bubble Generation Rate and Bubble Dissolution Rate into Water by A Simple Multi-Fluid Mixer with Orifice and Porous Tube, Experimental Thermal and Fluid Science, 2012, 41, 23-30.

Satker Pengembangan Sistem Penyehatan Lingkungan Permukiman (PSPLP), Laporan Akhir Review Masterplan TPA Piyungan. Yogyakarta: Dinas PUESDM Provinsi DIY, 2017.

Shabrina, Z.L.; Budhijanto, W., Peningkatan Produksi Biogas dari Lindi dengan Variasi Jumlah Zeolit Sebagai Media Imobilisasi Bakteri Anaerob. Prosiding Seminar Nasional Teknik Kimia Indonesia (SNTKI), Yogyakarta, 12-13 Oktober, 2015.

Siddique, M.N.I.; Wahid, Z.A., Achievements and Perspectives of Anaerobic Co-Digestion: A Review. Journal of Cleaner Production, 2018, 194, 359-371.

Sudibyo, H.; Guntama, D.; Budhijanto, W., Assessment of Start Up Mechanisms for Anaerobic Fluidized Bed Bioreactor in Series Based on Mathematical Simulation. Proceeding of International Seminar on Fundamental and Applied Chemical Engineering, Surabaya, 1-2 November 2016. 